\title{
Optimal design of efficient hole transporting layer free planar perovskite solar cell
}

\author{
Tianyue Wang ${ }^{1}$, Jiewei Chen ${ }^{1}$, Gaoxiang $\mathrm{Wu}^{1}$ and Meicheng $\mathrm{Li}^{1,2^{*}}$
}

\begin{abstract}
Hole transporting layer (HTL) free organometal halide perovskite solar cells have shown great promise in simplifying device architecture, fabrication process and enhancing stability. However, the simple elimination of the HTL from the standard sandwiched configuration suffers from relatively poor device performance; additionally, the mechanism of the HTL-free perovskite solar cell is still unclear. Herein, we applied a one-dimensional modeling program wxAMPS to investigate the planar HTL-free perovskite solar cells by adjusting the absorber thickness, doping and the absorber/back contact band alignment. The simulation results reveal the importance of the moderate absorber thickness as well as the p-doping perovskite rather than intrinsic as in sandwich structure to the overall device efficiency. In the meanwhile, reducing the mismatching of the absorber/back contact by using higher work function back contact material in replacement of commonly utilized Au electrode is more favorable to improve the device performance. Through optimizing, high performance HTL-free perovskite solar cell with efficiency approaching $17 \%$ could be achieved. This study is helpful in providing theoretical guidance for the design of HTL-free perovskite solar cells.
\end{abstract}

Keywords: HTL-free perovskite solar cells, wxAMPS simulation, absorber thickness, absorber doping, absorber/back contact band alignment

\section{INTRODUCTION}

Organometallic lead halide perovskite (e.g., $\mathrm{CH}_{3} \mathrm{NH}_{3} \mathrm{PbX}_{3}$ $(\mathrm{X}=\mathrm{I}, \mathrm{Br}, \mathrm{Cl}))$ as light absorber layers plays critical roles in thin film solar cells as reported that the state-of-art perovskite solar cell (PSC) utilizing this kind of material has made extraordinary performance with highest efficiency exceeding $22.1 \%[1,2]$. At present, most of the highly efficient PSCs employ sandwiched architecture of electron transporting layer (ETL)/perovskite absorber/hole transporting layer (HTL), which is initially derived from the solid state dye-sensitized solar cell. Specifically, the inorganic metallic oxides (e.g., $\mathrm{TiO}_{2}, \mathrm{ZnO}$ and $\mathrm{Al}_{2} \mathrm{O}_{3}$ ) are chosen as the ETL whilst some organic polymers and molecules (e.g., spiro-OMeTAD) are introduced as HTL $[3,4]$. However, due to the complex synthesis process, high fabricating cost and the low hole mobility of the spiro-OMeTAD as most commonly used HTL, its further application is inhibited [5]. Moreover, the spiro-OMeTAD layer shall lead to the electrode polarization and play critical roles in photocurrent density-voltage $(J-V)$ hysteresis phenomenon, which will affect the device stability [6].

Many researches are focusing on developing efficient HTL-free PSCs, which is favorable for process simplifications and cost reduction. Li et al. [7] reported an HTL-free device demonstrating unobvious $J-V$ hysteresis with a remarkable efficiency of $16 \%$. However, it still remains hard to facilely fabricate highly efficient devices and the demonstrated efficiency is mostly among $10 \%-12 \%$ [8-10]. And the reason why the HTL can be eliminated is not understood completely.

To have a better understanding of the HTL-free device operation mechanism and provide guidance for the device design with optimized efficiency, the one-dimensional simulator wxAMPS developed by Nankai University [11] is used for modeling the HTL-free PSC. This platform has been successfully used for simulating and understanding the mechanism of inorganic solar cells such as silicon, $\mathrm{CdTe}, \mathrm{Cu}(\mathrm{In}, \mathrm{Ga}) \mathrm{Se}_{2}$ (CIGS). Since the PSC is recognized to employ the p-n junction and the exciton in the perovskite

\footnotetext{
${ }^{1}$ State Key Laboratory of Alternate Electrical Power System with Renewable Energy Sources, North China Electric Power University, Beijing 102206, China

${ }^{2}$ Chongqing Materials Research Institute, Chongqing 400707, China

*Corresponding author (email: mcli@ncepu.edu.cn)
} 
material is typical Wannier-type, which is in analogy to that of Si and CIGS [12], thus this simulation software can be applied for modeling of the perovskite solar cell. To our knowledge, there have been several modeling works on the standard planar perovskite devices [12,13]; however, the investigation of characteristics of the HTL-free solar cells is still in lack. In our modeling, first, the reliability of the device modeling was verified by simulating the standard planar PSC in comparison with the real device. Then we investigated the HTL-free device by simply eliminating the HTL in the standard structure. As an approach to understand the operation mechanism of HTL-free PSC for the device optimization, the effects of the absorber thickness, doping and the band gap alignment between the absorber and the metal back contact were examined.

\section{DEVICE SIMULATION PARAMETERS}

In the simulation, the standard sandwiched planar PSC in configuration of $\mathrm{TiO}_{2} / \mathrm{MAPbI}_{3} /$ spiro-OMeTAD was simulated first as a baseline to verify the effectiveness of our approach. The HTL-free device was obtained with simply removal of the spiro-OMeTAD layer. Their schematic architectures are shown in Fig. 1a. Table 1 summarizes the basic device physical parameters for the simulation, most of which were selected from recent reported experimental works. The AM1.5 solar radiation spectrum was adopted as the light source and illuminated from the $\mathrm{TiO}_{2}$ side. The front contact is FTO with the working function set to be $-4.4 \mathrm{eV}$, and the back contact Au set to $-5.1 \mathrm{eV}$. Surface recombination rates of both the front and the back were set to $1 \times 10^{7} \mathrm{~cm} \mathrm{~s}^{-1}$. Energy levels of defects in the simulated thin film materials were located at the center of their bandgap with the Gaussian-type energetic distribution (characteristic energy $0.1 \mathrm{eV}$ ). The absorption coefficient of the perovskite layer was derived from Ref. [14].

Fig. $1 \mathrm{~b}$ plots the $J-V$ characteristics of the simulated stan- dard and HTL-free devices, respectively. An efficiency of $19.02 \%$ was obtained for the $\mathrm{TiO}_{2} / \mathrm{MAPb}_{3} /$ spiro-OMeTAD solar cell, closely reproducing the results reported by Ahn et al. [15]. In comparison, the HTL-free device is inferior in terms of the major photoelectric properties to the standard one. The simple elimination of the HTL layer based on the standard perovskite solar cell leads to a relatively poor device performance, hence, further optimization is required.

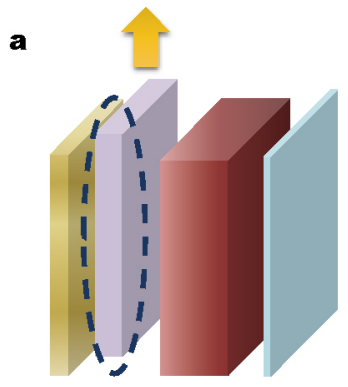

Au HTL Perovskite $\mathrm{TiO}_{2}$ A

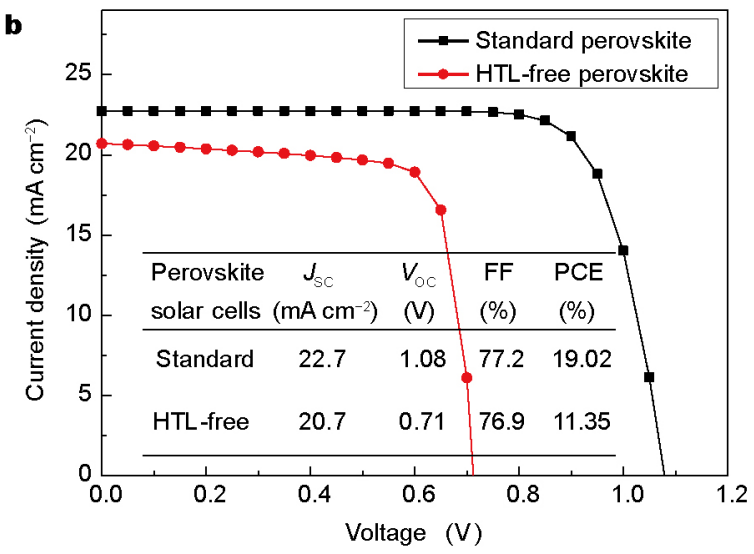

Figure 1 Schematic architectures (a) and $J$ - $V$ curves (b) of the standard planar perovskite solar cell and the derived HTL-free device model.

Table 1 wxAMPS parameters set for the baseline standard perovskite solar cell. For HTL-free device, HTL (spiro-OMeTAD) was simply removed from the structure

\begin{tabular}{cccc}
\hline Parameters and units & Compact $\mathrm{TiO}_{2}$ & $\mathrm{CH}_{3} \mathrm{NH}_{3} \mathrm{PbI}_{3}$ & Spiro-OMeTAD \\
\hline$\varepsilon_{\mathrm{r}}$ & $100[16]$ & $30[17]$ & $3[18]$ \\
$E_{\mathrm{g}}(\mathrm{eV})$ & 3.2 & $1.55[19]$ & $3.17[18]$ \\
$\chi(\mathrm{eV})$ & 4 & $3.9[8]$ & $2.05[18]$ \\
Thickness $(\mathrm{nm})$ & $30[2]$ & 300 & $150[2]$ \\
$\mu_{\mathrm{h}}$ or $\mu_{\mathrm{n}}\left(\mathrm{cm}^{2} \mathrm{~V}^{-1} \mathrm{~S}^{-1}\right)$ & $0.006[16]$ & $50[20]$ & 0 \\
$N_{\mathrm{a}}\left(\mathrm{cm}^{-3}\right)$ & 0 & 0 & $0.0001[21]$ \\
$N_{\mathrm{d}}\left(\mathrm{cm}^{-3}\right)$ & $5 \times 10^{19}[16]$ & $2.5 \times 10^{20}[20]$ & $3 \times 10^{18}$ \\
$N_{\mathrm{c}}\left(\mathrm{cm}^{-3}\right)$ & $1 \times 10^{21}$ & $2.5 \times 10^{20}[8]$ & 0 \\
$N_{\mathrm{v}}\left(\mathrm{cm}^{-3}\right)$ & $1 \times 10^{21}$ & $2.8 \times 10^{19}[22]$ \\
\end{tabular}


In the following, the effects of the absorber thickness, doping densities and the band alignment between the absorber and the metal contact on the HTL-free PSC are discussed.

\section{RESULTS AND DISCUSSION}

\section{Effect of the absorber thickness}

As a key part of PSC sited by light absorption and carrier generation, the perovskite absorber takes the dominance in determining the solar cell performance. Hence as the first step to better understand the working characteristics of the HTL-free device, we investigated the device performance as a function of the $\mathrm{MAPbI}_{3}$ thickness, as shown in Fig. 2a. When the thickness of the $\mathrm{MAPbI}_{3}$ is changed from 300 to $700 \mathrm{~nm}$, the short-circuit density $\left(J_{\mathrm{sc}}\right)$ and the open voltage $\left(V_{o c}\right)$ both show a slight increase then gradually saturate to a plateau $\left(\sim 21.82 \mathrm{~mA} \mathrm{~cm}^{-2}\right.$ and $0.75 \mathrm{~V}$, respectively). And the value of the fill factor (FF) also gets enhanced. An efficiency of more than $13 \%$ is obtained when the thickness reaches $700 \mathrm{~nm}$, which is increased approximately $2 \%$ compared to the original thin absorber film. This variation is ascribed to the more induced photo-electrons as a result of the enhanced light absorption. It is indicated by Fig. $2 \mathrm{~b}$ that the calculated quantum efficiency characteristics show an overall enhancement in the visible spectrum region with the increasing thickness of $\mathrm{MAPbI}_{3}$ film. Since the photocurrent $\left(J_{\mathrm{ph}}\right)$ can be expressed as [23]

$$
J_{\mathrm{ph}}=e \int \phi(\lambda) \operatorname{EQE}(\lambda) \mathrm{d} \lambda,
$$

where $e$ represents the electron charge, $\Phi(\lambda)$ is the spectral photon flux under AM 1.5, therefore the $J_{\text {sc }}$ elevates because more free carriers are converted from photos and collected by the electrode.

The simulation result indicates the design of much thicker absorber in HTL-free perovskite solar cell for better light harvesting, which is in accordance with the trend of the experimental result by Zhang et al. [24] who got higher efficiency of $\mathrm{TiO}_{2}$ /perovskite heterojunction device when increasing the film thickness from 190 to $630 \mathrm{~nm}$. Actually, the organic metal halides possesses ambipolar carrier transport property thus it can act also as excellent hole conductor, which is supported by many reports that the diffusion length in the active layer could exceed more than $1 \mu \mathrm{m}[25,26]$. Hence, relatively thick absorber layer will not cause bad recombination effect before the carriers travel through the absorber layer and reach the collecting electrodes. However, it should also be noted that the absorber thickness of the reported HTL-free cells is generally lower than the optimal simulated, which could be possible due to the pin-hole formation and more defects distribution during spinning thicker perovskite layer. But with optimized processing, higher quality thick perovskite film can be prepared for fabrication of high-efficiency HTL-free PSC.

\section{Effect of the absorber doping}

The absorber doping is another important factor in determining the property of PSC. Standard sandwiched PSC typically employs $n-\mathrm{i}-\mathrm{p}$ structure, in which ETL, perovskite layer and HTL demonstrate n-type, i-type, and p-type characteristics, respectively. However, the HTL-free device demonstrates the heterojunction structure, therefore we consider the perovskite absorber with intrinsic property that is commonly used in standard device is not suitable for HTL-free device and proper doping of absorber is more favorable. Here, by setting the perovskite to be p-type doping, the effect of the absorber doping density on the HTL-free device characteristic is explored.

Fig. 3 displays the parameters of the HTL-free PSCs with different absorber thickness as a function of absorber doping density. It can be seen that the efficiency $\left(V_{\mathrm{oc}}, J_{\mathrm{sc}}\right.$ or FF) curves with different absorber thickness unanimously
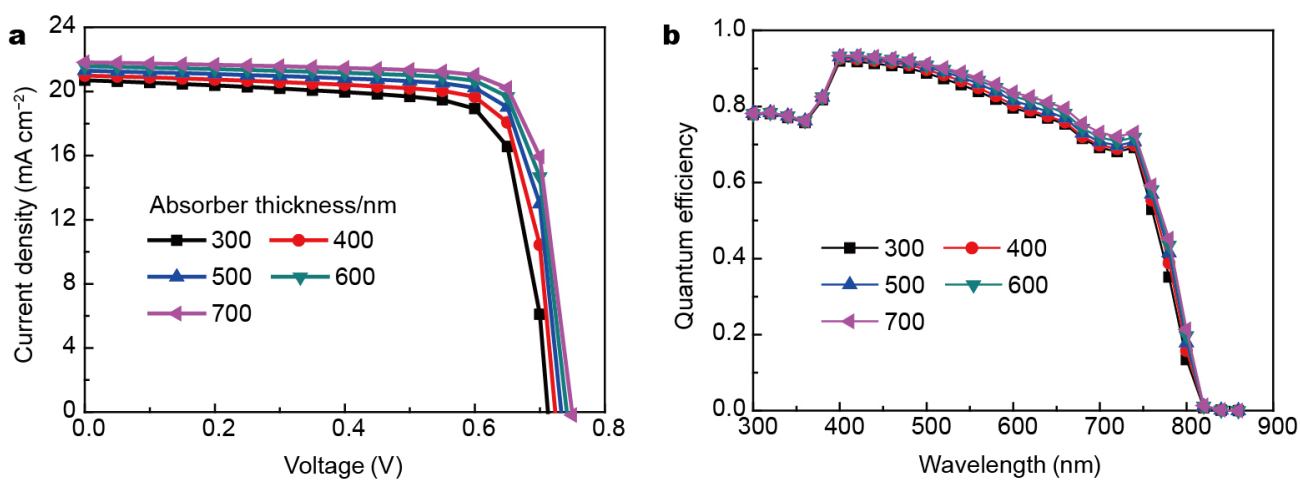

Figure 2 (a) $J$ - $V$ curves of the HTL-free PSC with varied thickness of absorber layer. (b) Quantum efficiency characteristics calculated with varying thickness of absorber layer. 
show the same variation trends, hence the thickness factor will not affect the functional relationship between the absorber doping and performance parameters. The strong effect of the doping density is observed on $V_{o c}$, which is the key factor to affect efficiency here. As Fig. 3b shows, when the doping is less than $1 \times 10^{15} \mathrm{~cm}^{-3}$, there is no evident change of $V_{\text {oc }}$ value, this is because of the relatively low doping density which does not change the intrinsic property of the absorber. But with doping increasing, for example, from $1 \times 10^{16} \mathrm{~cm}^{-3}$ to $1 \times 10^{18} \mathrm{~cm}^{-3}$, the $V_{\text {oc }}$ gets significantly enhanced. Similar tendency is also indicated by efficiency and FF curves in Fig. 3a and Fig. 3d, respectively. The dependence of higher $V_{\text {oc }}$ consequently enhanced efficiency on heavier absorber p-doping correlates with the intensified built-in electric field $\left(V_{\mathrm{D}}\right)$ between the $\mathrm{TiO}_{2} / \mathrm{MAPbI}_{3}$ interface, as shown in Fig. 4a. In heterojunction structure, $V_{\mathrm{D}}$ is described by

$$
V_{\mathrm{D}}=\frac{k_{\mathrm{B}} T}{q} \ln \left(\frac{N_{\mathrm{a}} N_{\mathrm{d}}}{n_{\mathrm{i}}^{2}}\right),
$$

where $k_{\mathrm{B}}$ is the Boltzmann constant, $T$ is the ambient temperature, $q$ is the electron charge, $N_{\mathrm{a}}$ is the acceptor density, $N_{\mathrm{d}}$ is the donor density, and $n_{\mathrm{i}}$ is the intrinsic carrier density. Since the $V_{\mathrm{D}}$ is positively related to the $N_{\mathrm{a}}$, the heavier absorber p-type doping could lead to higher $V_{\mathrm{D}}$ value, which shall exert effect on $V_{\text {oc }}$. However, the increase in doping could simultaneously induce large bulk recombination within the absorber layer (Fig. 4b), accordingly sacrificing the $J_{\mathrm{sc}}$ value (Fig. $3 \mathrm{c}$ ). Therefore, to get a balanced $V_{\text {oc }}$ and $J_{\text {sc }}$ with moderate efficiency of HTL-free device, we recommend the absorber to be heavily p-doped rather than intrinsic like in standard cell, and the doping density is better among the range of $1 \times 10^{16}$ to $1 \times 10^{17} \mathrm{~cm}^{-3}$.

\section{Effect of the band alignment between the absorber and the metal contact}

As reported by Minemoto et al. [27] that the HTL in standard PSC can work as a buffer for the perovskite/metal contact, the removal of HTL could cause the band mismatching and influence the device performance. For the reference HTL-free device simulated in Fig. 1b, there is a relatively large valence band offset $\left(\Delta E_{\mathrm{v}}\right)$ of $-0.35 \mathrm{eV}$ between the valence band of the absorber $\left(E_{\mathrm{v}-\text { absorber }}\right)$ and the work function of the metal $(\Phi)$ (here $E_{\mathrm{v} \text {-absorber }}$ is $-5.45 \mathrm{eV}$, $\Phi$ is -5.1 $\mathrm{eV}$ and $\left.\Delta E_{\mathrm{v}}=E_{\mathrm{v}-\mathrm{abs} s \mathrm{rber}}-\Phi\right)$, which could possibly exert bad effect on the device. Here, we adjusted the $\Delta E_{\mathrm{v}}$ value in a wide range from -0.35 to $0.2 \mathrm{eV}$ to study the impact of the $\triangle E_{\mathrm{v}}$ on the performance of the HTL-free solar cell and tried to search a proper band offset to optimize the device efficiency. In the following calculation, the thickness and
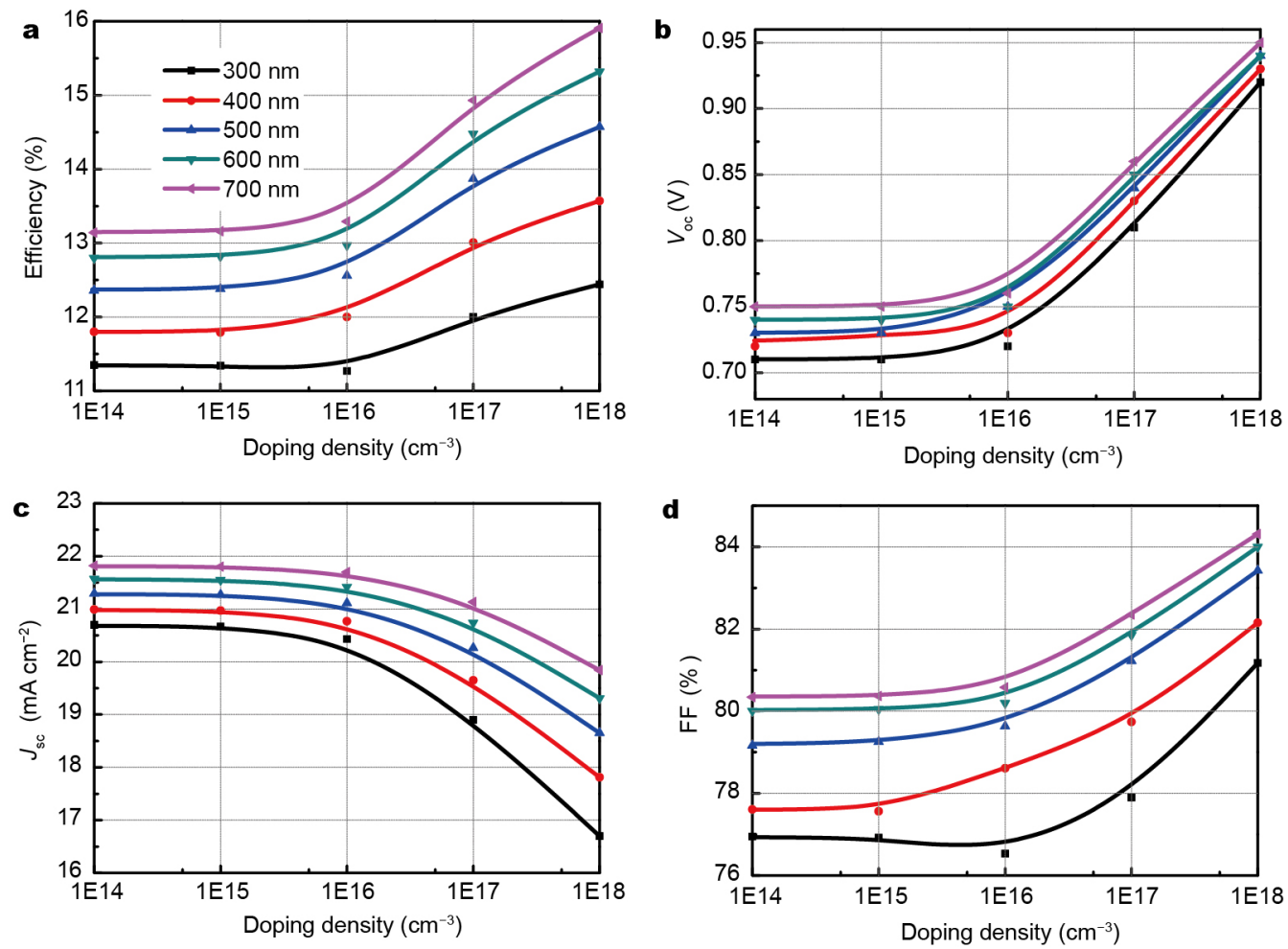

Figure 3 Parameters of the HTL-free perovskite cells with different absorber thickness as a function of absorber doping density. 

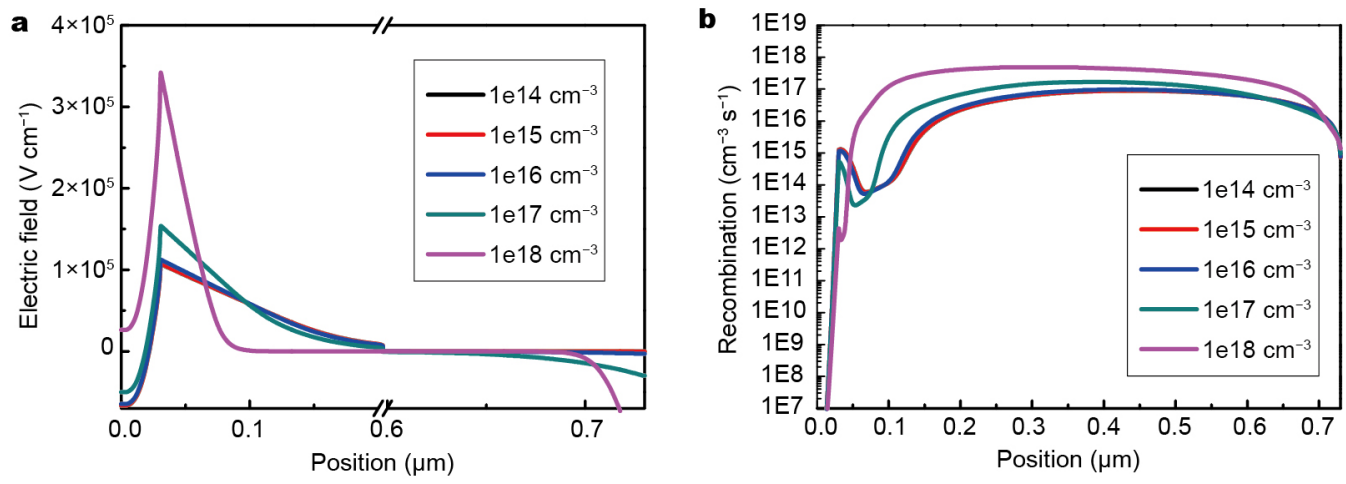

Figure 4 Simulation results of the built-in electric field (a) and recombination (b) in the HTL-free device with different absorber doping density. The thickness is fixed to $700 \mathrm{~nm}$.

doping of the absorber were set to be $700 \mathrm{~nm}$ and $1 \times 10^{17}$ $\mathrm{cm}^{-3}$, respectively, which were the optimized values adjusted above; and the variation of $\Delta E_{\mathrm{v}}$ was simulated through changing $\Phi$.

Fig. $5 \mathrm{~b}$ shows the impact of the $\Delta E_{\mathrm{v}}$ on the performance of the HTL-free solar cell. Here, the positive/negative values of $\Delta E_{\mathrm{v}}$ mean the $E_{\mathrm{v} \text {-absorber }}$ is shallower/deeper than $\Phi$. It can be seen that when the $E_{\mathrm{v}-\text { absorber }}$ is much deeper than $\Phi$, namely $\Delta E_{\mathrm{v}}<0$, there is a rather inferior efficiency for the device. We attribute this to the formation of Schottky junction at the absorber/metal interface as depicted in Fig. 5a that there is a slight shift down of the absorber band adjacent to the metal. But when the $E_{\mathrm{v} \text {-absorber }}$ is almost equal to or slightly shallower than $\Phi$, an up-shift band formed at the interface is energetically favorable for the hole transporting to metal, thus the energy loss is reduced. The highest efficiency approaching $17 \%$ is obtained at $\Delta E_{\mathrm{v}}=0.05 \mathrm{eV}$ and the optimal range of $\Delta E_{\mathrm{v}}$ is $-0.1-0.2 \mathrm{eV}$. This simulation reveals the importance of raising $\Phi$ value to improve the mismatching of the absorber/back contact interface and then increase the HTL-free device performance. Therefore, the commonly used $\mathrm{Au}$ electrode in standard perovskite solar

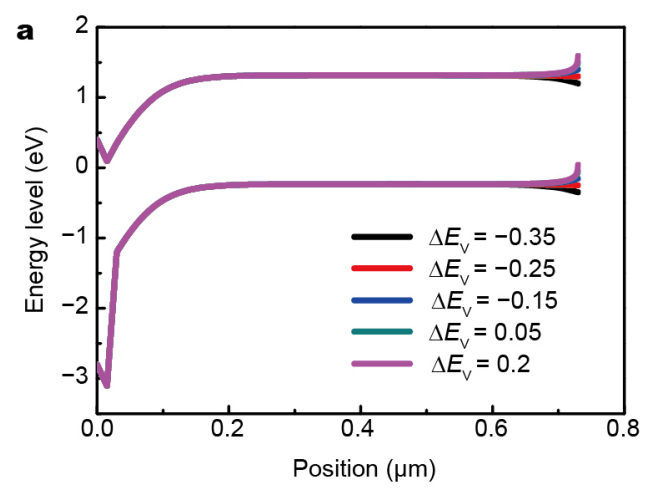

cell is not an ideal choice for HTL-free device due to the relatively small $\Phi$ which shall cause large $\Delta E_{\mathrm{v}}$. The choice of high work function back contact material is required to realize the perovskite/back contact band alignment.

\section{CONCLUSION}

The device simulation of the planar HTL-free PSC was performed using one-dimensional wxAMPS software. Several factors including the impacts of the absorber thickness, doping densities and the band alignment between the absorber/metal contact on the device performance were investigated. The simulation results reveal that 1 ) relatively thick absorber layer is required to increase overall device efficiency as a consequence of the light absorption enhancement; 2) the absorber shall be heavily p-type doped in HTL-free device rather than intrinsic as in standard configuration to elevate the charge separation capacity; 3 ) improving the mismatching of the absorber/back contact is important to enhance the device performance. The commonly used Au electrode in standard perovskite solar cell is not an ideal choice for HTL-free device. The choice of high work function back contact material is necessary to

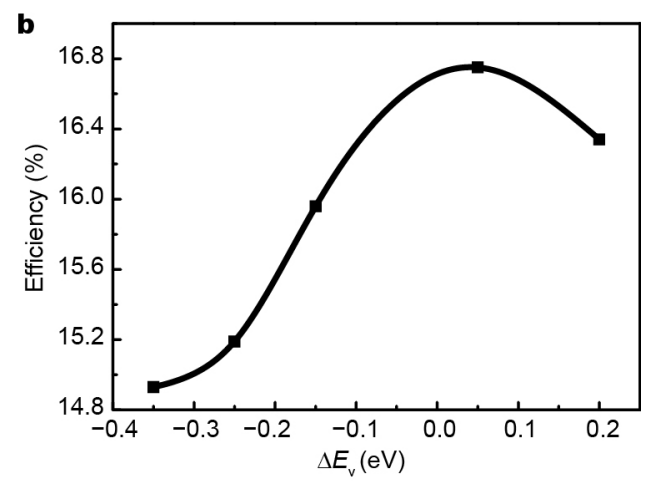

Figure 5 (a) Schematic band diagram of the HTL-free perovskite solar cell with varying $\Delta E_{\mathrm{v}}$. (b) The effect of the $\Delta E_{\mathrm{v}}$ on the performance of the HTL-free device. 
realize the perovskite/back contact band alignment. Notably, an efficiency above $17 \%$ is achieved for HTL-free perovskite solar cell with optimized parameters. This study will lead better understanding of the operation mechanism of the HTL-free PSC and favorable for its further efficiency improvement.

Received 27 July 2016; accepted 10 August 2016; published online 1 September 2016

1 http://www.nrel.gov/ncpv/images/efficiency_chart.jpg (Available 2016 August)

2 Wei D, Wang T, Ji J, et al. Photo-induced degradation of lead halide perovskite solar cells caused by the hole transport layer/metal electrode interface. J Mater Chem A, 2016, 4: 1991-1998

3 Lu H, Deng K, Yan N, et al. Efficient perovskite solar cells based on novel three-dimensional $\mathrm{TiO}_{2}$ network architectures. Sci Bull, 2016, 61: 778-786

4 Zhang J, Barboux P, Pauporté T. Electrochemical design of nanostructured $\mathrm{ZnO}$ charge carrier layers for efficient solid-state perovskite-sensitized solar cells. Adv Energy Mater, 2014, 4: 1400932

5 Nguyen WH, Bailie CD, Unger EL, et al. Enhancing the hole-conductivity of spiro-OMeTAD without oxygen or lithium salts by using spiro(TFSI $)_{2}$ in perovskite and dye-sensitized solar cells. J Am Chem Soc, 2014, 136: 10996-11001

6 Chen B, Yang M, Priya S, et al. Origin of $J-V$ hysteresis in perovskite solar cells. J Phys Chem Lett, 2016, 7: 905-917

7 Li Y, Ye S, Sun W, et al. Hole-conductor-free planar perovskite solar cells with 16.0\% efficiency. J Mater Chem A, 2015, 3: 18389-18394

8 Laban WA, Etgar L. Depleted hole conductor-free lead halide iodide heterojunction solar cells. Energy Environ Sci, 2013, 6: 3249-3253

9 Shi J, Luo Y, Wei H, et al. Modified two-step deposition method for high-efficiency $\mathrm{TiO}_{2} / \mathrm{CH}_{3} \mathrm{NH}_{3} \mathrm{PbI}_{3}$ heterojunction solar cells. ACS Appl Mater Interf, 2014, 6: 9711-9718

10 Tsai KW, Chueh CC, Williams ST, et al. High-performance holetransporting layer-free conventional perovskite/fullerene heterojunction thin-film solar cells. J Mater Chem A, 2015, 3: 9128-9132

11 Liu Y, Sun Y, Rockett A. A new simulation software of solar cells-wxAMPS. Solar Energy Mater Solar Cells, 2012, 98: 124-128

12 Minemoto T, Murata M. Device modeling of perovskite solar cells based on structural similarity with thin film inorganic semiconductor solar cells. J Appl Phys, 2014, 116: 054505

13 Liu F, Zhu J, Wei J, et al. Numerical simulation: toward the design of high-efficiency planar perovskite solar cells. Appl Phys Lett, 2014, 104: 253508

14 De Wolf S, Holovsky J, Moon SJ, et al. Organometallic halide perovskites: sharp optical absorption edge and its relation to photovoltaic performance. J Phys Chem Lett, 2014, 5: 1035-1039

15 Ahn N, Son DY, Jang IH, et al. Highly reproducible perovskite solar cells with average efficiency of $18.3 \%$ and best efficiency of $19.7 \%$ fabricated via lewis base adduct of lead(II) iodide. J Am Chem Soc, 2015, 137: 8696-8699

16 Wojciechowski K, Saliba M, Leijtens T, et al. Sub- $150^{\circ} \mathrm{C}$ processed meso-superstructured perovskite solar cells with enhanced efficiency. Energy Environ Sci, 2014, 7: 1142-1147

17 Liu W, Zhang Y. Electrical characterization of $\mathrm{TiO}_{2} / \mathrm{CH}_{3} \mathrm{NH}_{3} \mathrm{PbI}_{3}$ heterojunction solar cells. J Mater Chem A, 2014, 2: 10244-10249

18 Snaith HJ, Grätzel M. Electron and hole transport through mesoporous $\mathrm{TiO}_{2}$ infiltrated with spiro-MeOTAD. Adv Mater, 2007, 19: 3643-3647

$19 \mathrm{Noh} \mathrm{JH}, \mathrm{Im} \mathrm{SH}, \mathrm{Heo} \mathrm{JH}$, et al. Chemical management for colorful, efficient, and stable inorganic-organic hybrid nanostructured solar cells. Nano Lett, 2013, 13: 1764-1769

20 Stoumpos CC, Malliakas CD, Kanatzidis MG. Semiconducting tin and lead iodide perovskites with organic cations: phase transitions, high mobilities, and near-infrared photoluminescent properties. Inorg Chem, 2013, 52: 9019-9038

21 Snaith HJ, Grätzel M. Enhanced charge mobility in a molecular hole transporter via addition of redox inactive ionic dopant: implication to dye-sensitized solar cells. Appl Phys Lett, 2006, 89: 262114

22 Fonash S. Solar Cell Device Physics, 2nd edition. New York: Academic Press, 2010

23 Wang Y, Xia Z, Liang J, et al. Towards printed perovskite solar cells with cuprous oxide hole transporting layers: a theoretical design. Semicond Sci Technol, 2015, 30: 054004

24 Zhang F, Yang X, Wang H, et al. Structure engineering of hole-conductor free perovskite-based solar cells with low-temperature-processed commercial carbon paste as cathode. ACS Appl Mater Interf, 2014, 6: 16140-16146

25 Stranks SD, Eperon GE, Grancini G, et al. Electron-hole diffusion lengths exceeding 1 micrometer in an organometal trihalide perovskite absorber. Science, 2013, 342: 341-344

26 Frost JM, Walsh A. What is moving in hybrid halide perovskite solar cells? Acc Chem Res, 2016, 49: 528-535

27 Minemoto T, Murata M. Impact of work function of back contact of perovskite solar cells without hole transport material analyzed by device simulation. Curr Appl Phys, 2014, 14: 1428-1433

Acknowledgments This work was supported partially by the National High-tech R\&D Program of China (863 Program, 2015AA034601), the National Natural Science Foundation of China (91333122, 61204064, 51202067, 51372082, 51402106 and 11504107), PhD Programs Foundation of Ministry of Education of China (20120036120006 and 20130036110012), Par-Eu Scholars Program, and the Fundamental Research Funds for the Central Universities.

Author contributions Wang T performed the simulation and wrote this manuscript under the guidance of $\mathrm{Li} \mathrm{M}$; Chen J and Wu G contributed to the general discussion and article revision.

Conflict of interest The authors declare that they have no conflict of interest. 


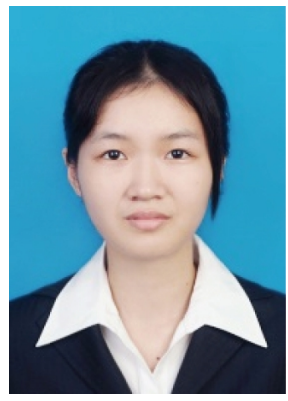

Tianyue Wang is a postgraduate candidate of the School of Renewable Energy at North China Electric Power University. She joined Prof. Li's New Energy Materials and Devices group in 2014, and her current interests include dye-sensitized solar cells and perovskite solar cells.

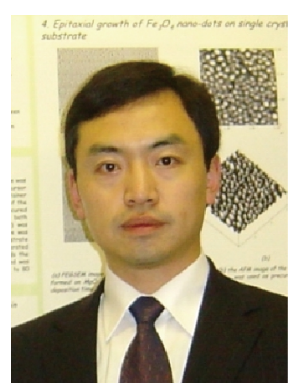

Meicheng Li is the director of the Center for New Energy Materials and Photoelectric Technology at the School of Renewable Energy in North China Electric Power University. His current focus is silicon nanowire based photovoltaic devices, including fundamental understanding, applied research and development (R\&D), and flexible device design. He also has interest in R\&D of perovskite solar cells, lithium ion battery system and other renewable energy devices (solar devices, sensors, etc.).

\section{高效无空穴传输层平板钙钛矿太阳能电池的优化设计}

王恬悦 ${ }^{1}$, 陈杰威 ${ }^{1}$, 吴高翔 ${ }^{1}$, 李美成 ${ }^{1,2^{*}}$

摘要 无空穴传输层的有机金属杂化钻钛矿电池因其结构简单、制备容易、稳定性强等优点, 展现出极大的发展潜力. 然而, 由标准三明 治结构的器件直接去除空穴传输层而得到的无空穴传输层的钻钛矿电池通常效率较低; 同时, 其详细工作机理尚不明确. 本文利用一维模 拟软件wxAMPS研究了无空穴传输层的平板钻钛矿电池的性能, 并分析改变吸收层的厚度、掺杂和吸收层/背接触的能带匹配对其性能的 影响. 模拟结果表明, 合适的吸收层厚度以及 $\mathrm{P}$ 型掺杂有利于提高无空穴传输层的平板钲钛矿电池的效率. 与此同时, 利用高功函数的背接 触材料取代传统的 $\mathrm{Au}$, 能明显减少吸收层/背接触的能带失配问题. 通过结构优化, 本文获得了效率高达 $17 \%$ 的无空穴传输层的平板钲钛矿 电池的设计,该工作可为高效的无空穴传输层的平板钙钛矿电池的实际设计提供一定理论指导. 